\title{
Application of Computer Graphic Technology in Animated Scene
}

\author{
Changyong Zhu , yunyun Wang , J iaxin Tang \\ Nantong Institute of Technology Nantong, Jiangsu 226002
}

Abstract:Animated scene design directedly refers to other styling design besides character design, which plays extremely important role in animated films. Scenes usually vary with plots of story, highlighting atmosphere and style of animation. Therefore, design of animated scene conveys characteristics of both technology and art. This article illustrates the specific application of computer graphic technology in animated scene, featuring the animation, the man on the stage, made by self.

Keywords:Animated scene, three dimentional animation, Peking Opera.

With the rapid development of digital media technology, the traditional two-dimensional animation scene can no longer meet people's visual needs. To cater to audiences, we could create three-dimensional space by using graphic and image technology in which we can make 3D animation with the sense of space and reality. To be more specific, we can build 3d model, set up material and texture, simulate realistic lightening, rig models and set up rendering to reach that purpose.

Three-dimensional animation has been widely spread in various fields. Specifically, in the field of digital games, 3D animation technology enables users to immerse themselves in the wonderland of virtual game world. In the field of digital entertainment, animation made with 3D technology seems to be more appealing, with its various styles of animated scene and distinctive characters. In the field of military, realistic battle scene could be simulated using 3D technology. Compared with 2D graphics, 3D graphics seem to be more vivid and stereoscopic, which are more likely to enhance audiences' visual comprehension. This measure benefits the creators of animation in their intention, bringing about a better experience to audience with more immersion and sense of realism.

Peking opera plays an important position in the long history of Chinese history. However, Peking opera culture is gradually weakening with the flowing of time, during which the birth, dan, net, end, and ugliness in Peking opera are gradually forgotten. Therefore, to protect this form of cultural heritage, three-dimensional animation is highly recommended, which depicts realistic scenery and provides a novel visual experience. In this animated short film, the ancient theater building group is used as a reference object. To present a unique architecture style, re-designing of Chinese ancient architecture is conducted during the production of animation On The Stage. The production of the animation scene combines both technology and art.

The production procedure of the animated film On the Stage is consisted of eight steps, which is summarized as scene design according to the script, research and study, redesign and planning of scene, 3D environment design and modeling, story broad planning, lightening and rendering, composition and postproduction. The animated film On the Stage will be introduced in this article.

\section{Story\& Background}

Peking opera, as an expression of traditional Chinese art form, conveys its spectacular expression and charm, staying popular among people who fancy art in the whole world range. There is one plot in the story that the performer who is making up behind the stage recalling the memory when he was performing on the stage with crowds of audience immersed in the performance. "Lan

Copyright (C) 2020 Zhu Changyong et al.

doi: $10.18282 / 1-$ e.v9i4.1697

This is an open-access article distributed under the terms of the Creative Commons Attribution Non-Commercial License (http://creativecommons.org/licenses/by-nc/4.0/), which permits unrestricted non-commercial use, distribution, and reproduction in any medium, provided the original work is properly cited.

\section{Conclusion}

Through the analysis of the above-mentioned number of affected people,we found that more and more countries and populations will be affected by environmental changes. The scale of EDP will become larger and larger,and the cultural loss caused by it will be inevitable.In this regard,our team has established a cultural loss risk assessment model to assess the continuous impact of EDP on cultural loss.

\section{References}

[1]Jason D.Söderblom(2008).Climate Change:National\&Regional Security Threat Multiplier for Australia[J].SECURITY SOLUTIONS.Pp.60-68.

[2]Emma Brindal(2007),Asia-Pacific:Justice for Climate Refugees[J].pp.240

[3]UN, The judgment of Huber in the Island of Palmas case 2 UN Doc RIAA829/838(1928) 
Fang, prepare it quickly, you should come on stage." Lan Fang Got up and went to the stage. As the accompaniment sounded, Lan Fang began to sing, and the audience was few and left. Facing the only audience under the stage, Lan Fang insisted on singing the opera, showing the love of Peking Opera culture and art from the older generation. The story itself, represent the awaking awareness to Chinese traditional art, which is correspondingly stressed in the production of the short animated film.

\section{Research\& Study}

Having decided the story, what is next is researching and gathering references. The work includes studying the topography, the topography, interior design of the Chinese traditional theatre including tables, chairs, tea sets, backstage and so on. During the research, details and information are required to be recorded which is for the convenience for what is coming after, animation design and production. The illustration 1-1 below represent some research progresses and its direction.
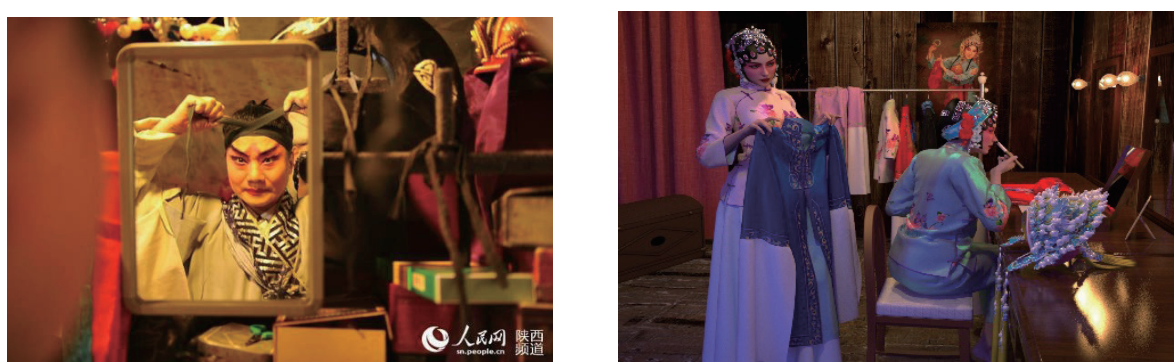

Figure 1-1 Research and Study of Chinese Peking Opera

Design of Animated Scene and Production

On the basis of the research in the early stage, design work is processed in depth and meticulously. To be more specific, the animated scene and props are designed according to the living environment and background during that time, as is illustrated in the figure 1-2 below.
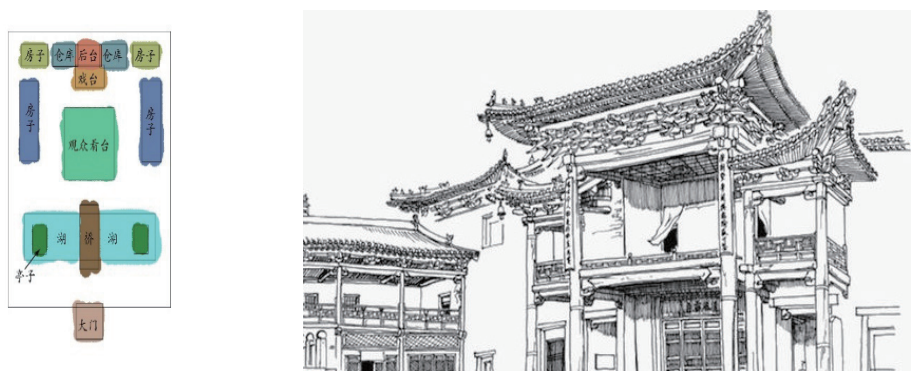

Figure 1-2 Sketches and Planning

\section{D Environment Design\& Modeling}

The 3D environment design is mainly based on the hand-drawn environment illustration. The software used during the process is the 3D animation production software Autodesk Maya. Polygon modeling technology is adopted for the production of 3D models. The production is progressed from coarseness to exquisite, during which the coarse models are exported into the software Z-Brush for finer sculpture with the texture and materials attached. The figure 1-3 displays parts of the production progress.
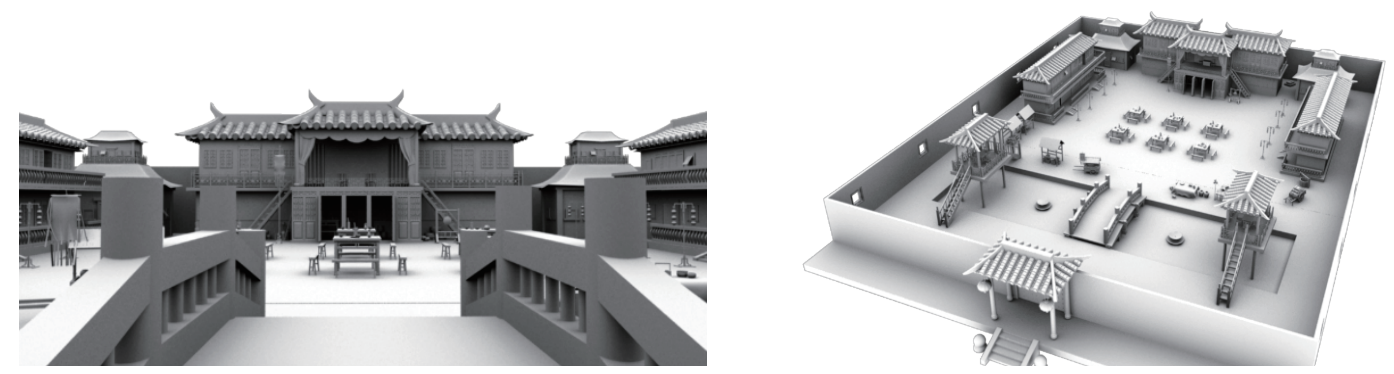

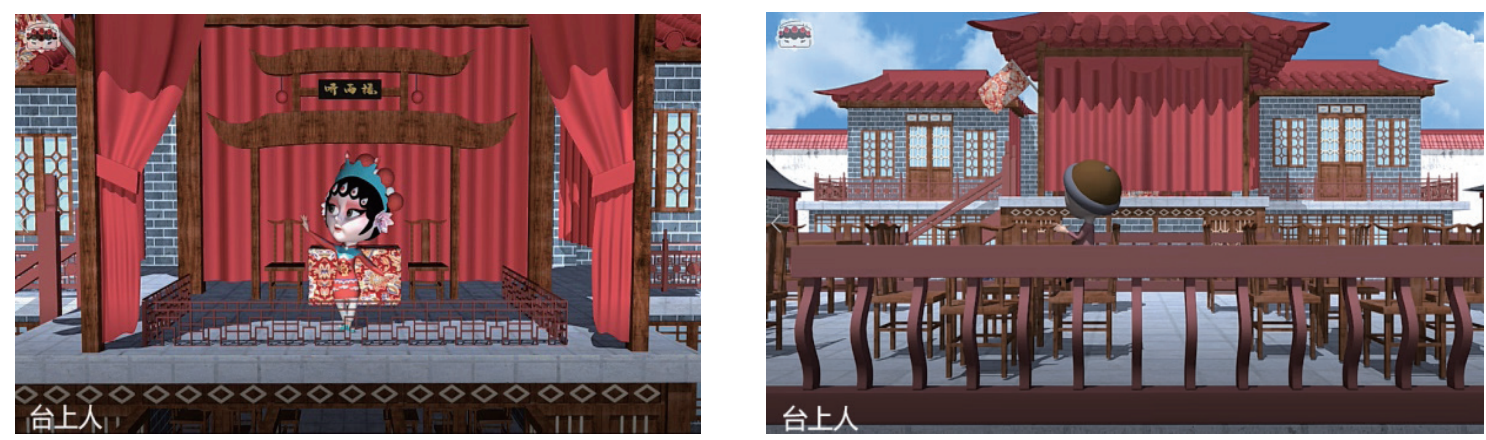

Figure 1-3 Design of animated scene, production and texture design

\section{Story Board\& Camera movement}

The story board planning, based on the script, is fundamental in the camera settings and displaying in 3D animation software. Four camera movement are mainly used in the animated film, which are pan shot, tilt shot, zoom shot and crane shot. The virtual camera set in the software is shown in Figures 1-4.
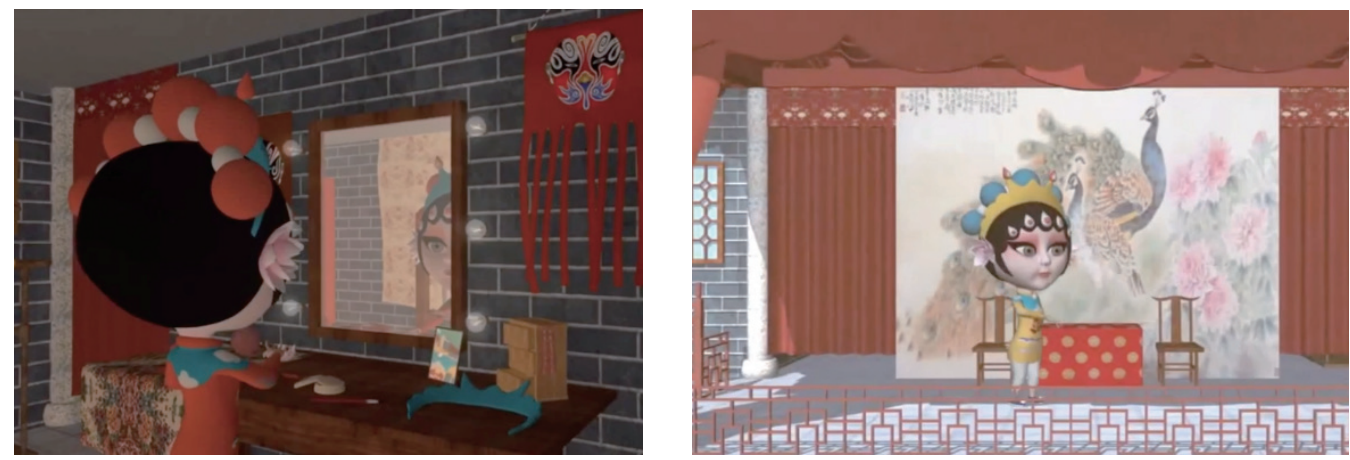

Figure 1-4 Camara Set in Animation

\section{Lighting\& Rendering}

The lighting is set to maximize the simulation of natural lighting and artificial lighting. The lighting in 3D software includes floodlight, such as light from sun and candle, and direction lights such as lights from touches, searchlights and other sources with illumination directions. The function of lighting is not only illuminating the environment, but also casting shadows and helping to present atmosphere. In this animated film, three-point lighting is set in the scene, which correspondingly refers to main light, supplementary light and back light. Specifically, main light determines the main light direction with most brightness, producing the main shadow of the character. It is usually placed three-quarters of the front, that is, 45 degrees to the left or right of the front of the character.

The role of the supplementary light is to soften the shadows produced by the main light, especially the face area, often placed close to the camera. The backlight is to strengthen the main character and show its outline, so that the main character stands out from the background. The background light is usually placed in three quarters of the back.

During the production process of animation scenes, rendering plays a very important role. Rendering is to integrate the lights, materials, shadows, textures and actions in the scene into one picture, so as to achieve the sense of realism and create space of the picture. Instant rendering covers all rendering elements, including material surface attributes, reflection and refraction information, lighting, global illumination, etc., which allows us to easily control the picture and grasp the rendering effect in time ${ }^{[1]}$. The rendering method varies according to the renderer used. In this digital short film production process, Mental ray is mainly applied. Mental Ray has been integrated into Maya since Maya5.0. MentalRay for Maya supports Maya 's excellent material system. Users can use Maya 's traditional methods to adjust the material and render The results are almost the same ${ }^{[2]}$, as shown in Figure 1-5.
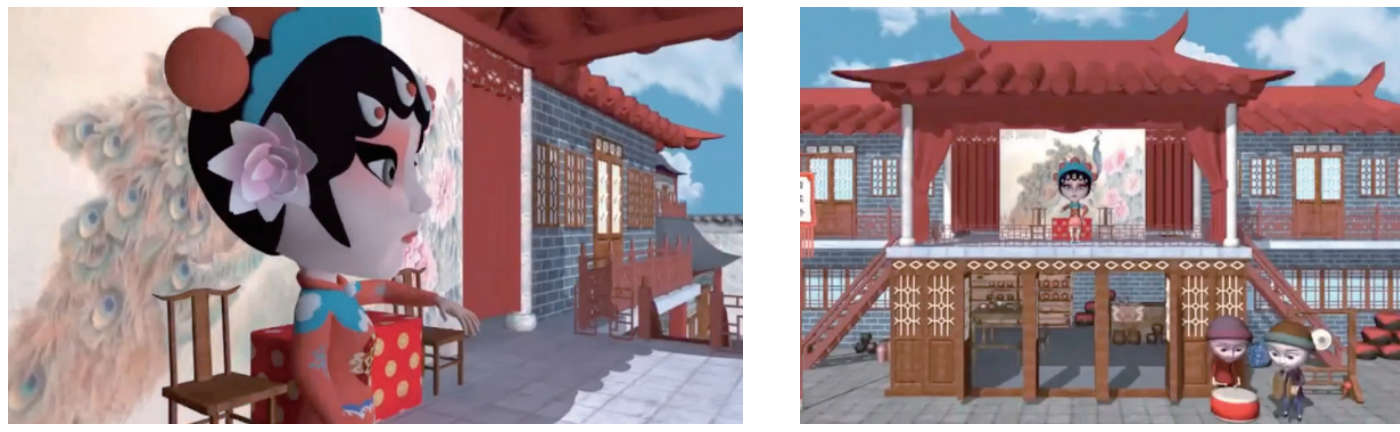

Figure 1-5 Animated Scene rendered with Mental Ray 


\title{
Trauma Narratives in Hiroshima Mon Amour
}

\author{
Wenxi Guo* \\ 1New York University,NY 10003, the United States of America
}

Abstract:This paper is based on the film Hiroshima Mon Amour,analyzing it through Vickroy's trauma narratives.It aims to give an analysis of its plot,characterization, and narrative discourse in relation to the fragmentation, dissociation of the character's identity, the capacity to produce symbols, and the composition of trauma incarnate.

Keywords:Film analysis; Hiroshima Mon Amour; Trauma narratives; Narrative Discourse

\section{INTRODUCTION}

Hiroshima Mon Amour is a French Left Bank romantic drama film directed by Alain Resnais,and released in 1959.It documented a story between a French-Japanese couple about post-war trauma and memory,being an epitome of the nonlinear storyline.It adopted a modernistic filmic technique that intersperses different time and space with newsreel footage and fictional storyline.Through a symbolic romantic story,it reflects the traumatic experience and the fear of forgetfulness of war.

The trauma narratives will manifest itself in perspectives of fragmentation, dissociation of the characters'identities, the ability to produce symbols,static images and motifs related with trauma, the composition of trauma incarnate,and dialogical conceptions of witnessing in relation to Laurie Vickroy's theory in Trauma and Survival in Contemporary Fiction. With Tom Gunning's theory of narrative discourse and Michel Chion's theory of sound,I will analyze the sequences through these aspects to discuss their cultural,and social reasons and effects.

\section{METHODOLOGY}

The overall methodology will be Laurie Vickroy's theory about trauma narratives, with the analytical approaches of Gunning's narrative discourse, and Chion's sound to further discuss certain elements in relation to the trauma theory.I will further explain these three theories and their relations in this section.

Initially,from Gunning's theory,it is possible for us to distinguish different narrative discourse levels derived from Genette's categories:the pro-filmic,the enframed image,and the process of editing ${ }^{[1]}$.Furthermore,Chion's theory of sound functions as"added value"in audiovisual illusion to display an expressive and informative value to create the definite impression,and accentuates the meaning in reality,bridge the relation between visual images and something one hears. The narrative discourse,as a basic technical tool of sequences/film analysis,will combine with the functions of sound to give a general and specific analysis of filmic elements that will contribute to trauma theories, and further facilitate the analysis of post-war female trauma and presentation of trauma in relation with moving images.

Vickroy's theory of trauma narratives demonstrates different sections and presentations of trauma.First,the narratives of"fragmentation"indicate that something"creates or maintains a profound disturbing sense of self,"and the attempt to resist it becomes a common strategy of the protagonists of trauma fiction" ${ }^{[2]}$.Both she and he share the fragmentation in the trauma theory.

Copyright (C) 2020 Wenxi Guo

doi: 10.18282/1-e.v9i4.1698

This is an open-access article distributed under the terms of the Creative Commons Attribution Non-Commercial License (http://creativecommons.org/licenses/by-nc/4.0/), which permits unrestricted non-commercial use, distribution, and reproduction in any medium, provided the original work is properly cited.

\section{Composing}

The postproduction of 3D animation is to compose the animation clips, sound and other materials made according to the script planned previously, with editing using non-linear editing software. Therefore, the animation could be composed as one.

The production of animated scene is not only a category in art design, but also a fusion of digital media technology and a product of the combination of technology and art. With the aid of computer technology, it is possible to break through the limitations of time and space and maximize the performance of animation.

\section{Reference}

[1] Lin Zhe. Analysis of 3D animation rendering technology [J]. Modern Film Technology, 2014 (09): 22-25.

[2] Bian Dan. Exploration based on the application of the renderer Mental Ray [J]. Computer Knowledge and Technology, 2017,13

(09): 207-208. 